NBER WORKING PAPER SERIES

\title{
DOES QUITTING SMOKING INCREASE OBESITY? EVIDENCE FROM ACCOUNTING FOR MISREPORTING
}

\author{
Rusty Tchernis \\ Keith F. Teltser \\ Arjun Teotia \\ Working Paper 29701 \\ http://www.nber.org/papers/w29701 \\ NATIONAL BUREAU OF ECONOMIC RESEARCH \\ 1050 Massachusetts Avenue \\ Cambridge, MA 02138 \\ January 2022
}

This research did not have any sources of financial support. The views expressed herein are those of the authors and do not necessarily reflect the views of the National Bureau of Economic Research.

NBER working papers are circulated for discussion and comment purposes. They have not been peer-reviewed or been subject to the review by the NBER Board of Directors that accompanies official NBER publications.

(C) 2022 by Rusty Tchernis, Keith F. Teltser, and Arjun Teotia. All rights reserved. Short sections of text, not to exceed two paragraphs, may be quoted without explicit permission provided that full credit, including $\odot$ notice, is given to the source. 
Does Quitting Smoking Increase Obesity? Evidence From Accounting for Misreporting Rusty Tchernis, Keith F. Teltser, and Arjun Teotia

NBER Working Paper No. 29701

January 2022

JEL No. I1,I12

\begin{abstract} estimate suggests reduced smoking accounts for $6 \%$ of the concurrent rise in obesity.

Rusty Tchernis

Department of Economics

Andrew Young School of Policy Studies

Georgia State University

P.O. Box 3992

Atlanta, GA 30302-3992

and NBER

rtchernis@gsu.edu

Keith F. Teltser

Department of Economics

Andrew Young School of Policy Studies

Georgia State University

Atlanta, GA 30303

US

kteltser@gsu.edu

Arjun Teotia

Georgia State University

ateotia1@student.gsu.edu
\end{abstract}

Smoking and obesity are the two leading causes of preventable deaths in the United States. Because smoking is subject to heavy government intervention, understanding the effect of smoking on obesity is important in determining the extent of unintended costs or benefits of such intervention. The existing literature on this question is mixed among studies using experimental and observational data, which we attempt to reconcile by accounting for misreporting in observational data. We use self-reported data from the Behavioral Risk Factor Surveillance System (BRFSS), cigarette taxes to instrument for changes in smoking, and survey completion to instrument for misreporting. Starting with the baseline two-stage least squares (2SLS) estimator common in the earlier observational literature, we obtain similar estimates suggesting quitting smoking substantially reduces BMI. However, we find the results are sensitive to specification, functional form, and the presence of misreporting. We show that accounting for misreporting using the 2-step estimator developed by Nguimkeu et al. (2019) yields estimates consistent with the experimental literature; quitting smoking has a small positive effect on BMI. Our preferred 


\section{Introduction}

Smoking and obesity are the two leading causes of preventable deaths in the United States. ${ }^{1}$ Almost $40 \%$ of adults in the United States are obese (Hales et al. (2017)), while roughly $14 \%$ of adults in the U.S. smoke according to the CDC. ${ }^{2}$ In Figure 1, we show that smoking decreased from roughly $22 \%$ to $15 \%$ between 2002 and 2017 among Behavioral Risk Factor Surveillance System (BRFSS) respondents, while average body mass index (BMI) rose from roughly 26.75 to 28.25 during the same time period. While these trends do not present causal evidence, they raise the question of whether the decline in smoking has contributed to rising obesity. Because smoking is subject to heavy government intervention, accurately estimating the effect of smoking on obesity is important in determining the extent of unintended costs or benefits of such intervention.

Using Grossman's human capital model of health, we can consider health a capital stock that depreciates over time but can be replenished by investment (Grossman, 1972). Assuming an individual starts at her optimal body weight, both smoking and weight gain represent disinvestments. Cigarettes contain nicotine, which suppresses appetite and increases one's metabolic rate. Thus, smoking cigarettes tends to reduce body weight, all else equal. However, smoking also reduces lung capacity, which may restrict physical activity and thereby increase body weight. Because the causal effect of smoking on obesity is theoretically ambiguous, determining the true relationship is an empirical question.

There exists a large literature examining the causal relationship between smoking and obesity, though the findings are quite mixed. Using BRFSS data from 1984 to 1999, Chou et al. (2004) suggest that reduced smoking increases body mass index (BMI) by finding increasing cigarette prices have a large positive effect on BMI. Using BRFSS data from 1984 to 2002/2005, Gruber and Frakes (2006) and Courtemanche (2009) examine this relationship more closely using cigarette taxes instead of cigarette prices. ${ }^{3}$ The authors find that an increase in cigarette taxes (i.e. reduced

\footnotetext{
${ }^{1}$ See https://www.cdc.gov/tobacco/data_statistics/fact_sheets/health_effects/ tobacco_related_mortality/index.htm and https://www.commonwealthfund.org/blog/2018/ rising-obesity-united-states-public-health-crisis

${ }^{2}$ See https://www.cdc.gov/tobacco/data_statistics/fact_sheets/fast_facts/index.htm, last accessed February 19,2020

${ }^{3}$ Note that Courtemanche (2009) actually uses BRFSS data to examine the robustness of his central estimates obtained using the National
} 
smoking) reduces BMI. However, several other studies around the same time use different observational data or approaches to causal identification to suggest that reduced smoking increases BMI (Baum, 2009; Fang et al., 2009; Liu et al., 2010). Moreover, Courtemanche et al. (2018) also find that reduced smoking increases BMI using a randomized trial of smoking cessation treatments and clinically-measured carbon monoxide levels.

The mixed findings highlight the complexity of identifying the causal effect of smoking on BMI. In particular, two concerns stand out from the literature. First, estimates are sensitive to different approaches to identification and choice of specification. Second, estimates are sensitive to the source of data, which raises the concern that results obtained from self-reported data (as opposed to clinically-measured experimental data) are biased and/or inefficient due to systematic misreporting. For example, studies have found that accounting for misreporting can significantly impact estimates of marijuana usage, as well as the magnitude and direction of estimated effects of nutritional assistance programs on BMI and obesity (Greene et al., 2017; Almada et al., 2016; Nguimkeu et al., 2019). A large body of medical research has revealed widespread underreporting based on comparisons of self-reported smoking to biochemical indicators of tobacco intake (e.g., Gorber et al., 2009; Nesson, 2017). To our knowledge, no one has previously examined how misreporting impacts estimates of the effect of smoking on BMI.

In this paper, we aim to reconcile the mixed findings in the existing literature and provide a clearer picture of the relationship between smoking and obesity. To do this, we use BRFSS data from 2002 to 2017 to examine how specification choice and accounting for misreporting affect estimates of the effect of smoking on BMI. In particular, we employ a variety of linear and nonlinear instrumental variables approaches, using cigarette taxes as plausibly exogeneous shifters of smoking behavior. To account for misreporting, we use the 2-step estimation procedure proposed by Nguimkeu et al. (2019). First, we replicate the findings of Gruber and Frakes (2006) and Courtemanche (2009) using our more recent data, obtaining estimates suggesting that quitting smoking reduces BMI by 4.2 (27 pounds for someone who is 5'7' tall and 180 pounds). Second,

Longitudinal Survey of Youth. Indeed, the author finds that both data sources yield similar estimates. 


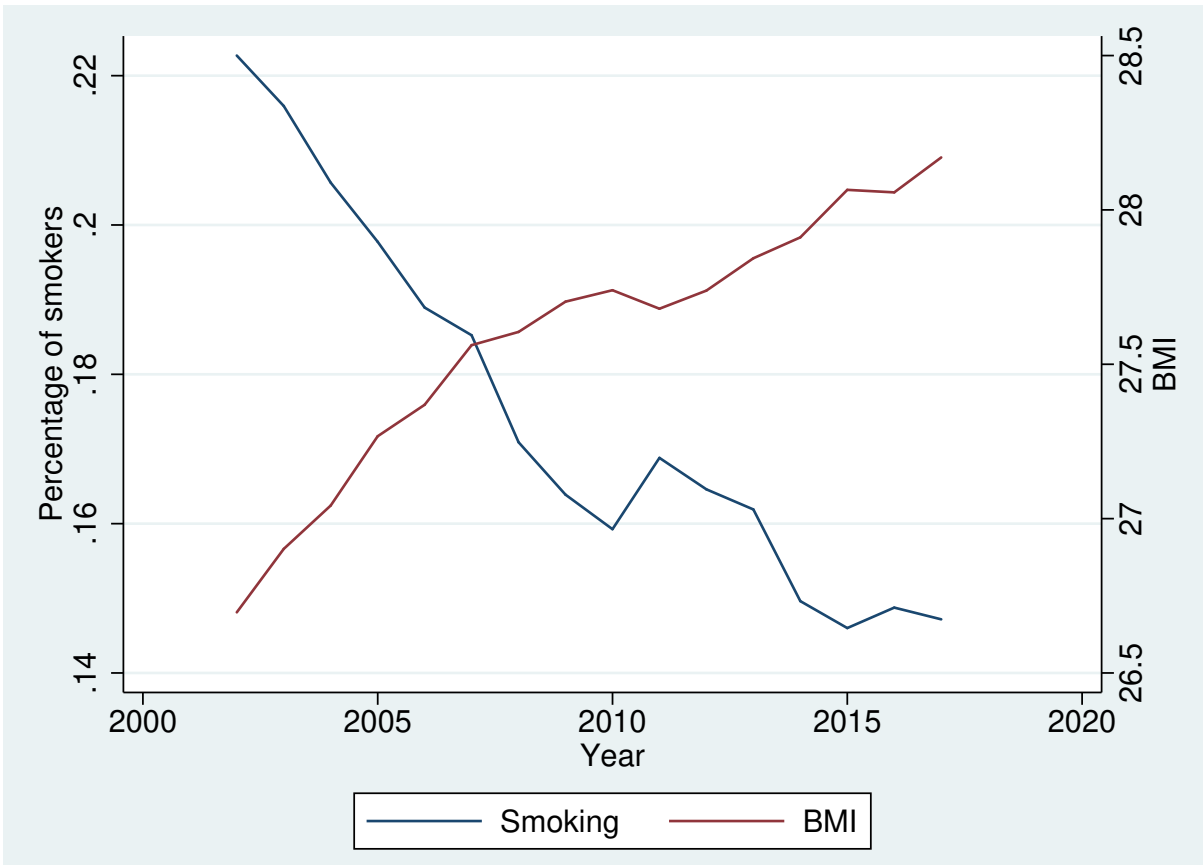

Figure 1: Trends in smoking and obesity (BRFSS 2002-2017)

using a nonlinear first stage to predict smoking status and accounting for misreporting via the 2step procedure, we obtain estimates consistent with the experimental literature in both sign and magnitude. That is, we find quitting smoking increases BMI by 1.06, or about 7 pounds for someone who is 5' 7" tall and 180 pounds. To show the intermediate impact of using a nonlinear first stage to predict smoking status, we present estimates from both a control function and nonlinearfits-as-instruments approach. Here, we find estimates of roughly the same or larger magnitude as 2SLS but is opposite-signed, suggesting again that quitting smoking increases BMI. These findings suggest that both specification choice and accounting for misreporting may help reconcile the discrepancies among earlier studies. From 2002-17, our findings suggest that the decline in smoking explains roughly $6 \%$ of the concurrent rise in obesity, suggesting that increased obesity may be an unintended consequence of anti-smoking policy efforts.

The rest of the paper is organized as follows. Section 2 provides a more detailed review of the literature. Section 3 describes our data. Section 4 develops our various approaches to estimation and presents our results. Section 5 concludes. 


\section{Literature Review}

Instrumental variables (IV) approaches are common in the literature on the relationship between smoking and body weight. This is because smoking behavior may be endogenous, as individuals generally self-select into smoking. There are also concerns about reverse causality. That is, body weight may affect an individual's decision of whether or not to smoke (Cawley et al., 2004; Rees and Sabia, 2010). The literature has primarily used cigarette prices and taxes as plausibly exogeneous instruments, as they shift the cost of smoking but do not seem to have a direct causal relationship with BMI.

In Table 1, we catalog the main estimates from earlier literature on the relationship between smoking and BMI. First, Chou et al. (2004) use BRFSS data from 1984 to 1999 to estimate the determinants of BMI and obesity, and find large positive effects of cigarette prices. Assuming cigarette prices affect individuals only through smoking, these results suggest that reductions in smoking contribute to increases in body weight. In contrast, using BRFSS data from 1984 to 2002

and cigarette taxes instead of prices, Gruber and Frakes (2006) examine this question more closely and find that reduced smoking reduces BMI and obesity rates. The authors propose two possible explanations for why their results differ from those of Chou et al. (2004). First, taxes may be better instruments than prices, as variation in prices may be driven by factors affecting both BMI and demand for cigarettes. Second, Gruber and Frakes (2006) use month-year fixed effects rather than quadratic time trends to more flexibly control for unobservable location-invariant shocks over time. However, the authors caution that their IV estimates may be implausibly large, as they suggest that individuals who quit smoking are 56\% less likely to be obese. Courtemanche (2009) revisits Gruber and Frakes (2006) using both BRFSS and the National Longitudinal Survey of Youth (NLSY), and also finds that reduced smoking reduces BMI and obesity rates. Moreover, the author shows that this result is robust to a range of alternative linear specifications.

Other studies around the same time, however, challenge these findings. Baum (2009) use the NLSY for years 1979 through 2002 to estimate the body-weight effects of real cigarette prices and taxes. Using a standard differences-in-differences approach, they find that an increase in the cost 
of cigarettes (i.e. a reduction in smoking) increases BMI and obesity rates. Fang et al. (2009) use data from the China Health and Nutrition Survey (CHNS), leveraging number of cigarettes smoked and the local per-pack price of the most popular cigarette brand as IVs. Similarly, they find that reduced smoking increases BMI, though they find small and statistically insignificant effects on obesity rates. Liu et al. (2010) use worksite smoking bans along with BRFSS data from 1998 to 2006 to find further evidence suggesting reduced smoking increases obesity rates.

Moreover, a more recent study by Courtemanche et al. (2018) uses clinical measurements from an experimental setting to provide additional consistent evidence. In particular, they use data from a randomized trial of smoking cessation treatments. Rather than relying on self-reported smoking, they observe clinically-measured carbon monoxide levels. They find that, in the short run, quitting smoking leads to a gain of 10-11 pounds at average height. In the long run, this effect increases to 11-12 pounds. We view these as the most credible estimates to date. The main limitation of Courtemanche et al. (2018) is that the study focuses on individuals who were trying to quit smoking in 1990-1994, which may cast doubt on whether similar estimates would be obtained in more recent years.

If nothing else, the mixed evidence highlights the challenges inherent in estimating the causal relationship between smoking and body weight. Misreporting is one significant challenge that it seems the literature on smoking and obesity has not yet tackled. Nesson (2017) finds about $46 \%$ of adolescent smokers misreport smoking status. Subjects in the study knew ahead of time that they would later be clinically tested for evidence of smoking activity, suggesting $46 \%$ may be an underestimate of misreporting in regular survey data like the BRFSS. That said, adolescents may also be more likely to misreport than adults. In any case, this level of misreporting can cause a large bias in the second stage. Nguimkeu et al. (2019) and Brachet (2008) both provide insight on this issue, in that the authors discuss how expansion bias occurs when misreporting is fixed and exogenous. Unfortunately, it is not straightforward to quantify how large this bias will be given a particular level of misreporting. Almada et al. (2016) also speak to this issue, examining the relationship between supplemental nutrition assistance (SNAP) and obesity in the presence 
of misreporting. The authors find that traditional linear IV estimates fall outside of the Manski bounds, providing further evidence that traditional linear IV can be quite unreliable in the presence of misreporting. More generally, Mogstad and Wiswall (2010) show the fragility of traditional linear IV approaches when the underlying relationship is nonlinear, while Guo and Small (2016) show that a control function IV approach can be much more efficient than two-stage least squares under certain conditions.

In the following sections, we aim to reconcile the mixed literature to provide a clearer picture of the true relationship between smoking and obesity. In particular, we argue that specification choice, functional form, and misreporting may help explain the apparent discrepancies across previous studies.

\section{Data}

We start with repeated cross-sectional data from the 2002 through 2017 waves of the BRFSS, which is a health-focused telephone survey conducted by the CDC. The survey collects information on health-related risky behaviors among U.S. residents, as well as chronic health conditions and use of preventative services. The BRFSS was first established in 1984, with 12,258 participants across 14 states. In 2017, the data include approximately 430,000 participants from all 50 states and the District of Columbia. Starting in 2002, the BRFSS contains information on interviewer performance and whether a respondent fully or partially completed the interview. Because we use this information to account for possible misreporting, we restrict our main estimation sample to the years 2002-2017.

In particular, we use the core module that includes self-reported height, weight, demographics, tobacco use, health status, and chronic health conditions. Following Gruber and Frakes (2006), we restrict our sample to respondents under 65 years of age. After also dropping observations with missing data for our key variables of interest, our sample contains roughly 3.6 million observations. We calculate BMI using respondents' self-reported height and weight, removing extreme outliers 
by dropping the bottom and top $1 \%$ of BMI values, which leaves us with a range of 17.75 to 46.39. Using CDC guidelines, we define a current smoker as one who reported smoking at least 100 cigarettes during their lifetime, and, at the time of participation, reported that they currently smoke either some days or every day. We also use several additional individual-level covariates, including marital status, race, education, and income. Similar to Gruber and Frakes (2006), we include age-by-gender interaction terms.

We supplement our BRFSS data with information on state excise cigarette taxes from the CDC's Tax Burden on Tobacco (TBOT) dataset. The TBOT reports tax rates at the end of October every year, along with the exact date(s) of any rate changes, which we use to determine monthly tax rates. We convert nominal tax rates to 2017 dollars using the Consumer Price Index for All Urban Consumers (CPI-U). Because the BRFSS asks individuals about their behavior over the past 30 days, we follow the previous literature in assigning tax rates to individuals based on the month preceding their survey interview. Finally, we include a time-varying measure of state-level unemployment from the Bureau of Labor Statistics (BLS) to account for economic conditions that may be correlated with body weight, smoking, and/or cigarette taxes.

In Table 2, we report the summary statistics for our main estimation sample derived from the 2002-2017 BRFSS files, which keeps only the respondents for whom all of our control and outcome variables of interest are non-missing. In this sample, $21 \%$ of respondents are identified as smokers. The average BMI among smokers is 27.18 , which is lower than the average non-smoker BMI of 27.77. In addition, we see that $78 \%$ of individuals are white, $8 \%$ are black, and $7 \%$ are hispanic. In addition, $43 \%$ of individuals are male, $27-28 \%$ have a high school and/or technical degree, and $38 \%$ are college graduates. Note that, in our analyses, we weight by the stratified sampling weights provided by the CDC. Using survey weights is important in this context, as BRFSS oversamples different population groups across different years depending on the guidance from the CDC.

In the sample, the mean (real) cigarette excise tax is $\$ 2.22$. The highest observed nominal tax is $\$ 4.35$ in New York and Connecticut in 2017, while the lowest in 2017 is \$0.17 in Missouri (see Ta- 
ble 3). In addition to substantial across-state variation in tax magnitudes, taxes vary substantitally across time within states. Between 2002 and 2017, there were 132 nominal tax increases.

Finally, the variable we use to account for misreporting is called "Final Disposition" in the BRFSS data. This indicates whether the respondent fully completed their interview, and we use it to predict whether an individual is less likely to answer questions truthfully. We find that approximately $7 \%$ of respondents in our sample only partially complete their interview.

\section{Estimation and Results}

In this section, we start by obtaining naïve OLS estimates of the relationship between smoking and BMI via OLS, and then estimate a variety of IV specifications. Throughout, we follow the previous literature in specifying the following structural linear model of the relationship between BMI and smoking:

$$
B M I_{i s t}=\alpha S_{i s t}+X_{i s t} \beta+\tau_{t}+\mu_{s}+\epsilon_{i s t}
$$

where $S$ indicates current smoking status for individual $i$ in state $s$ and month-year $t . X$ is a vector of individual- and state-level covariates, $\tau_{t}$ are time fixed effects, ${ }^{4} \mu_{s}$ are state fixed effects, and $\eta_{\text {ist }}$ is an idiosyncratic error term. $X$ includes individuals' income, race, marital status, education, age, gender, an age-by-gender interaction term, and state unemployment rate from the BLS.

In the first row, second panel of Table 4, we find that the naïve OLS estimate of the relationship between smoking and BMI is negative. For OLS, and all our other estimation approaches, we present three specifications. Column 1 presents the results when we only include state and quarter-year fixed effects. Column 2 presents the results when we only include the set of covariates (income, race, marital status, educational attainment, age-by-gender dummies, and state unemployment rate). Column 3 presents the results when including both the fixed effects and covariates. In our preferred specification, column 3, we estimate that quitting smoking is associated with a BMI increase of 0.7 (2.5\% relative to average BMI of 27.65). For someone who is 5' 7' tall

\footnotetext{
${ }^{4}$ Note that we use quarter-year, not month-year, for our time fixed effects throughout to improve computational feasibility for the nonlinear portions of our analyses.
} 
and 180 pounds $(\mathrm{BMI}=28.2)$, this corresponds to an increase of roughly 4.5 pounds.

Our first IV approach is a standard two-stage least squares (2SLS) approach, which follows Gruber and Frakes (2006) closely. Next, we implement a 2-step estimator proposed by Nguimkeu et al. (2019) to account for the possibility of misreporting, which entails using a nonlinear first stage. Finally, to show the reader the impact of using a nonlinear first stage without accounting for misreporting, we obtain estimates from two alternate IV approaches. The first is a corrected version of the "forbidden regression." The second is a control function approach. Following the large economic literature on smoking, we use cigarette taxes to instrument for smoking status throughout these analyses. In addition, we weight our regressions throughout by the BRFSSprovided stratified sampling weights. ${ }^{5}$

\subsection{Two-Stage Least Squares}

In this approach, following Gruber and Frakes (2006), the first stage is specified as a linear probability model:

$$
S_{i s t}=\psi T a x_{s t}+X_{i s t} \phi+\tau_{t}+\mu_{s}+\eta_{i s t}
$$

Tax is the identifying instrument, which reflects the real excise cigarette tax (in 2017 \$). The corresponding second stage is given by:

$$
B M I_{i s t}=\alpha \hat{S}_{i s t}+X_{i s t} \beta+\tau_{t}+\mu_{s}+\epsilon_{i s t}
$$

where $\hat{S}$ is predicted smoking status from the first stage, and $\alpha$ is the causal parameter of interest.

Table 4 presents the results from the analysis using 2SLS. In the first stage (row 1, top panel, column 3), we estimate that a $\$ 1$ increase in the real cigarette excise tax significantly reduces the probability of being a smoker by 0.6 percentage points. We also present the F-statistic, which is 16.4 for this specification, suggesting that cigarette taxes are indeed a strong predictor of smoking behavior. Note that we do not find a statistically significant direct relationship between BMI and

\footnotetext{
${ }^{5}$ See appendix for non-weighted estimates.
} 
cigarette taxes, where the reduced form estimate presented in column 3 of the middle panel suggests that a $\$ 1$ tax increase statistically insignificantly reduces BMI by 0.025 . In row 2, column 3 of the bottom panel, our 2SLS estimate suggests that quitting smoking reduces BMI by roughly 4.2 (or a reduction of 27 pounds for someone 5' 7" tall and 180 pounds). While the standard error of the 2SLS estimate is roughly 50\% larger than the coefficient, the magnitude is in line with the estimate of 5.70 (s.e. = 2.91) from Gruber and Frakes (2006) using BRFSS data from 1984-2002 and our replication of that estimate of 5.34 (s.e. $=3.25$ ). That said, as pointed out by the authors themselves, it still seems to be unreasonably large when compared to the rest of the literature.

In addition, it is also worth noting that the 2SLS estimates are relatively unstable across specifications. When including fixed effects but no covariates, the 2SLS estimate is similar but smaller (3.49). However, when including covariates and excluding fixed effects, the sign flips and the magnitude is much smaller $(-0.79$, more in line with the stable "naïve" OLS estimates of -0.4 to -0.7). Moreover, the 2SLS standard errors reveal that the point estimates are quite imprecise, encompassing a wide range of both positive and negative values within the $95 \%$ confidence interval. For example, the main estimate of 4.2 has a standard error of roughly 6.3. Going two standard deviations in both directions yields a $95 \%$ confidence interval of $[-8.404,16.804]$. In the results presented in the following subsections, we see that the preferred 2-step, NFI, and CF estimates all fall within this interval. This imprecision appears to be driven, not by a weak first stage, but by a weak reduced form relationship between cigarette taxes and BMI. Estimating our preferred specification suggests that a $\$ 1$ increase in cigarette taxes reduces average BMI by 0.025 with a $95 \%$ confidence interval of [-0.109, 0.059].

In the following subsections, we show (1) the sign of the estimates is consistently negative when using a nonlinear first stage, (2) conditional on including covariates, the results are not nearly as sensitive to the inclusion of fixed effects when using a nonlinear first stage, and (3) using a nonlinear first stage with the full set of controls yields much more precise IV estimates, roughly an order of magnitude smaller than the 2SLS counterpart. Moreover, we show that the results are stable across all three specifications when using a nonlinear first stage that accounts for misreport- 
ing, ranging only from approximately -0.50 to -1.06 . It is possible that the gain in precision is a byproduct of specifying a more accurate first stage functional form, which perhaps improves the precision of the resulting second stage IV estimator.

\section{$4.2 \quad$ 2-step estimator}

Next, using a 2-step estimator allows us to account for misreporting of smoking in the BRFSS data, following Nguimkeu et al. (2019). Suppose the outcome variable of interest, BMI, is a function of correctly-measured exogeneous covariates $X$ and the (true) smoking indicator, $S^{*}$. In particular, we specify:

$$
B M I_{i s t}=\alpha S_{i s t}^{*}+X_{i s t} \beta+\tau_{t}+\mu_{s}+\epsilon_{i s t} .
$$

where $\alpha$ is the key parameter of interest.

We model true smoking status $\left(\mathrm{S}^{*}\right)$ as a function of $\mathrm{X}$ and the exogenous instrument Tax:

$$
S_{i s t}^{*}=\mathbf{1}\left(\theta \operatorname{Tax}_{s t}+X_{i s t} \beta+\tau_{t}+\mu_{s}+v_{i s t} \geqslant 0\right)
$$

However, we only observe self-reported smoking status, S, which is a surrogate of one's true smoking status. Thus, we can consider $S_{i}=S_{i}^{*} d_{i}$, where $d$ is an indicator of misreporting. If an individual truthfully reports their smoking status, $d=1$ ( 0 otherwise). Note that $S=S^{*}$ for true non-smokers regardless of misreporting. That is, we assume a true non-smoker would not falsely report smoking. Next, we model $d$ as a function of observable covariates $X$ and disposition Disp:

$$
d_{i s t}=\mathbf{1}\left(\rho \operatorname{Disp}_{i s t}+X_{i s t} \gamma+\tau_{t}+\mu_{s}+u_{i s t} \geqslant 0\right)
$$

such that:

$$
\begin{aligned}
& S_{i s t}=S_{i s t}^{*} d_{i s t} \\
& =\mathbf{1}\left(\theta \operatorname{Tax}_{s t}+X_{i s t} \beta+\tau_{t}+\mu_{s}+\nu_{i s t} \geqslant 0 ; \rho D i s p_{i s t}+X_{i s t} \gamma+\tau_{t}+\mu_{s}+u_{i s t} \geqslant 0\right) .
\end{aligned}
$$


In the first step, we estimate equation 7 using a partial observability probit model, which allows us to predict each individual's true smoking status, $\hat{S}^{*}$. In the second stage, we estimate equation 4 , substituting $\hat{S}^{*}$ in for $S^{*}$. The resulting $\alpha$ is the 2 -step estimate of the true causal effect of smoking on obesity when accounting for endogenous misreporting.

The results of this approach, presented in row 2 of the top panel of Table 4, yield very similar first-stage estimates of the effect of cigarette taxes on smoking. In our preferred specification (column 3), the first-stage F-statistic is 36.95, again suggesting that cigarette taxes are strong predictors of smoking. Turning to row 3 of the bottom panel, we find a negative relationship between smoking and obesity. However, here we find that quitting smoking leads to an increase in BMI of only 1.06 (about 7 pounds for someone 5' 7' tall and 180 pounds). This estimate is much closer to the experimental 2SLS estimate obtained by Courtemanche et al. (2018), who find that quitting smoking increases BMI by 2.2 (about 14 pounds) when using clinically-measured carbon monoxide levels to determine smoking behavior among participants in a smoking cessation randomized trial. Moreover, we find that this 2-step approach yields a much more stable pattern of estimates across our three specifications, where the estimates only range between -0.50 and -1.06 . Our preferred estimate of -1.06 is also considerably more precise than its 2SLS counterpart, with a $95 \%$ confidence interval of only [-2.057, -0.061].

\subsection{Nonlinear First Stage Without Accounting for Misreporting}

In the following two sub-subsections, we present to the reader the intermediate impact of using a nonlinear first stage without accounting for misreporting. In particular, we obtain estimates from two alternate IV strategies: nonlinear-fits-as-instruments and a control function approach.

\subsubsection{Nonlinear-Fits-as-Instruments}

First, we would like to estimate the relationship between smoking and BMI by using a probit model for the first stage to obtain predicted smoking status, and then substituting predicted smoking status for observed smoking status in a linear second stage. However, this was famously dubbed the "for- 
bidden regression" by Hausman, since only a linear first stage estimated via OLS is "guaranteed to produce first-stage residuals that are uncorrelated with fitted values and covariates" (Angrist and Pischke, 2008).

To correct for this, we use the nonlinear-fits-as-instruments (hereafter, NFI) approach suggested by Newey (1990). The NFI approach has three stages, which we describe below as stages zero, one, and two. Stage zero is given by:

$$
S_{i s t}=\psi \operatorname{Tax}_{s t}+X_{i s t} \phi+\tau_{t}+\mu_{s}+\eta_{i s t}
$$

which we estimate as a probit model to obtain predicted smoking status $\hat{S}$. Then, in stage one, we estimate $S$ as a function of $\hat{S}$ along with our set of controls:

$$
S_{i s t}=\theta \hat{S}_{i s t}+X_{i s t} \gamma+\tau_{t}+\mu_{s}+u_{i s t} .
$$

Finally, we estimate stage two of the NFI model, where BMI is specified as a function of predicted smoking from stage one, $\tilde{S}$, and the set of controls:

$$
B M I_{i s t}=\alpha \tilde{S}_{i s t}+X_{i s t} \beta+\tau_{t}+\mu_{s}+\epsilon_{i s t} .
$$

Note that this approach identifies $\alpha$ using both taxes and nonlinearities in stage zero. While using nonlinearities as identifying information may be somewhat undesirable, Newey (1990) shows that the resulting estimates are more efficient when the probit model is a better approximation of the first-stage conditional expectation function.

Turning to Table 4, row 3, column 3 of the top panel reveals a very similar first stage relationship as in 2SLS. Specifically, the estimate suggests that a $\$ 1$ increase in the real cigarette excise tax reduces the probability of being a smoker by 0.6 percentage points. The first stage F-statistic is 11.38, again, suggesting that cigarette taxes are a strong predictor of smoking. However, turning to row 4 , column 3 of the bottom panel, we find that the estimated effect is similar in magnitude to 
2SLS but the direction of the relationship is flipped. That is, our NFI estimate suggests that quitting smoking increases BMI by 6.2 (roughly 40 pounds for someone 5' 7' tall and 180 pounds). In this specification, as opposed to 2SLS, the standard errors are much smaller and the coefficient is highly statistically significant. That said, the magnitude still appears to be unreasonably large relative to the rest of the literature. While the corresponding NFI estimate when we include fixed effects and exclude covariates is particularly unreasonably large $(-20.9)$ and imprecise (s.e. $=16.2)$, when we include covariates the estimates are not as sensitive as 2SLS to the inclusion of fixed effects $(-4.5$ without fixed effects vs. -6.2 with fixed effects).

\subsubsection{Control Function}

Second, we estimate the causal relationship of interest using a nonlinear (probit) first stage via the control function (hereafter, CF) approach. Again, the first stage is given by:

$$
S_{i s t}=\psi \operatorname{Tax}_{s t}+X_{i s t} \phi+\tau_{t}+\mu_{s}+\eta_{i s t} .
$$

After estimating this probit model, we obtain the residuals (Res) and use them as a covariate in the second stage. The second stage is given by:

$$
B M I_{i s t}=\alpha S_{i s t}+\delta \operatorname{Res}_{i s t}+X_{i s t} \beta+\tau_{t}+\mu_{s}+\epsilon_{i s t}
$$

where $S$ is self-reported smoking status, Res are the residuals from the first stage, along with the usual set of additional controls. The estimated $\alpha$ from the second stage is our causal parameter of interest.

The results presented in row 3, column 3 of the top panel of Table 4 reflect the first stage estimates for both the NFI and CF approaches, as they both use the exact same first stage specification. Turning to row 5, column 3 of the bottom panel, we see that the estimate is quite similar to the NFI estimate (negative relationship) but slightly larger in magnitude (-7.4 vs. the NFI estimate of -6.2). As in the NFI specification, the standard error is much smaller than that of the 2SLS estimate 
and the coefficient of interest is highly statistically significant. Again, while the corresponding CF estimate when we include fixed effects and exclude covariates is unreasonably large (-11.3) and imprecise (s.e. $=8.6$ ), when we include covariates the estimates are not as sensitive as 2SLS to the inclusion of fixed effects (-5.5 without fixed effects vs. -7.4 with fixed effects).

Even though the sign flips when using a nonlinear first stage, which is in line with the experimental literature, the estimates are still unreasonably large compared to the rest of the literature on the relationship between smoking and BMI. This highlights the potential importance of accounting for misreporting in smoking status via the 2-step procedure, which has a substantial impact on the stability of the estimates while bringing them back within a reasonable range of values.

\subsection{Including Disposition as a Second Instrument in 2SLS, NFI, and CF}

In this subsection, we re-estimate our preferred 2SLS, NFI, and CF approaches including both cigarette taxes and disposition (i.e. our proxy for misreporting) as instrumental variables. This helps us address the concern of whether our 2-Step estimates are simply the byproduct of introducing a second instrument rather than addressing misreporting specifically. We present these results in Table 5. The notable results are the following. First, including disposition as a second instrument has virtually no effect on the NFI and CF estimates. The NFI estimate is -6.481 and the CF estimate is -7.694 , compared to 6.210 and -7.366 , respectively, in Table 4. The standard errors are also very similar. However, including disposition as a second instrument has an enormous impact on the 2SLS estimate, yielding a much larger and opposite-signed coefficient of -20.131. Despite the large standard error of 9.643 , this estimate is statistically significant at the $5 \%$ level. This result further highlights the extreme sensitivity, and thus relative unreliability, of the fully-linear IV approach in examining the effect of smoking on BMI using survey data and cigarette taxes as an instrument. 


\subsection{Heterogeneity}

Finally, we use the 2-step estimator to examine heterogeneity in the effects of smoking on BMI across age, gender, and U.S. census region. While we will focus primarily on presenting the 2-step results, note that we also present the results of OLS, 2SLS, NFI, and CF estimation for comparison purposes.

Turning first to Table 6, our 2-step estimates suggest that cigarette taxes have a slightly larger impact on smoking among respondents aged 41-65: a reduction of 1.1 percentage points in the probability of being a smoker for a $\$ 1$ increase in taxes compared to 0.8 points for those aged 18-40. In terms of the effects of smoking status on BMI, however, we find that quitting smoking has a larger positive impact on BMI among the 18-40 age group: an increase of 4.2 (27 pounds for someone 5' 7' and 180 pounds) compared to only 0.8 (5 pounds) among those aged 41-65.

Next, looking at Table 7, our 2-step estimates suggest that cigarette taxes have a substantially larger impact on smoking among female respondents: a 1.2 percentage point smoking reduction compared to 0.6 for men. Interestingly, we find that quitting smoking results in a significantly larger weight gain for men than women: 6.9 BMI points for men compared to a statistically insignificant decrease of 1.3 BMI points for women.

Finally, in Table 8, we examine regional differences in the relationship between smoking and BMI. Looking in row 3 of the bottom panel, we find that quitting smoking increases BMI by 3.2 to 4.5 in the northeast and midwest, while we find no statistically discernable relationship among respondents in the southern and western regions of the United States.

\section{Conclusion}

Because smoking and obesity are the two leading causes of preventable deaths in the United States, and are thus subject to heavy government intervention, understanding the effect of smoking on obesity is important in determining the costs or benefits of such intervention. To date, the literature examining this relationship has been quite mixed, with some studies finding a positive effect and 
others finding a negative effect. In this paper, we show that carefully considering functional form and accounting for misreporting may help explain the conflicting evidence across previous experimental and observational studies of the relationship between smoking and obesity.

In particular, we show that using a nonlinear first stage to estimate the relationship between cigarette taxes and smoking status yields a negative relationship between smoking and BMI, which is consistent with the experimental literature and some of the earlier literature using observational data. Moreover, we show that accounting for misreporting and using a nonlinear first stage with observational data yields estimates of similar sign and magnitude to this body of work. For example, our preferred estimate suggests that quitting smoking increases BMI by 1.06 (about 7 pounds for someone 5' 7' and 180 pounds), which is quite similar to the experimental estimate of 2.2 (14 pounds) from Courtemanche et al. (2018), but quite different from the estimated decrease in BMI of 4.2 to 5.7 (27 to 36 pounds) when following the approach of Gruber and Frakes (2006) using 2SLS and observational data.

Using our estimation sample and incorporating survey weights, the proportion of smokers declined from $25.4 \%$ in 2002 to $18.8 \%$ in 2017 while BMI rose from 26.7 to 27.9. Multiplying the 6.6 percentage point decline in smoking by our preferred estimate of 1.06 yields a BMI increase of 0.07, which explains roughly $6 \%$ of the overall BMI increase of 1.2 across the same time period. This suggests increased obesity may be an unintended consequence of anti-smoking policy efforts.

More broadly, our work shows how certain functional form choices and failing to account for misreporting might result in biased and/or inefficient estimates when using survey data and instrumental variables methods. These considerations have receive little attention in the literature on the effects of smoking. As such, a key contribution of this paper is to demonstrate how researchers might effectively address functional form and misreporting issues in future work. 


\section{Bibliography}

Almada, L., McCarthy, I., and Tchernis, R. (2016). What can we learn about the effects of food stamps on obesity in the presence of misreporting? American Journal of Agricultural Economics, 98(4):997-1017.

Angrist, J. D. and Pischke, J.-S. (2008). Mostly harmless econometrics: An empiricist's companion. Princeton university press.

Baum, C. L. (2009). The effects of cigarette costs on bmi and obesity. Health Economics, 18(1):319.

Brachet, T. (2008). Maternal smoking, misclassification, and infant health. SSRN Working Paper.

Cawley, J., Markowitz, S., and Tauras, J. (2004). Lighting up and slimming down: the effects of body weight and cigarette prices on adolescent smoking initiation. Journal of health economics, 23(2):293-311.

Chou, S.-Y., Grossman, M., and Saffer, H. (2004). An economic analysis of adult obesity: results from the behavioral risk factor surveillance system. Journal of health economics, 23(3):565587.

Courtemanche, C. (2009). Rising cigarette prices and rising obesity: Coincidence or unintended consequence? Journal of Health Economics, 28(4):781-798.

Courtemanche, C., Tchernis, R., and Ukert, B. (2018). The effect of smoking on obesity: Evidence from a randomized trial. Journal of health economics, 57:31-44.

Fang, H., Ali, M. M., and Rizzo, J. A. (2009). Does smoking affect body weight and obesity in china? Economics \& Human Biology, 7(3):334-350.

Gorber, S. C., Schofield-Hurwitz, S., Hardt, J., Levasseur, G., and Tremblay, M. (2009). The accuracy of self-reported smoking: A systematic review of the relationship between self-reported and cotinine-assessed smoking status. Nicotine \& Tobacco Research, 11(1):12-24.

Greene, W., Harris, M. N., Srivastava, P., and Zhao, X. (2017). Misreporting and econometric modelling of zeros in survey data on social bads: An application to cannabis consumption. Health economics.

Grossman, M. (1972). On the concept of health capital and the demand for health. Journal of Political economy, 80(2):223-255.

Gruber, J. and Frakes, M. (2006). Does falling smoking lead to rising obesity? Journal of health economics, 25(2):183-197.

Guo, Z. and Small, D. S. (2016). Control function instrumental variable estimation of nonlinear causal effect models. The Journal of Machine Learning Research, 17(1):3448-3482.

Hales, C., Carroll, M., Fryar, C., and Ogden, C. (2017). Prevalence of obesity among adults and youth: United states, 2015-2016. NCHS data brief, (288):1-8.

Liu, F., Zhang, N., Cheng, K.-W., and Wang, H. (2010). Reduced smoking and rising obesity: Does smoking ban in the workplace matter? Economics Letters, 108(3):249-252.

Mogstad, M. and Wiswall, M. (2010). Linearity in instrumental variables estimation: problems and solutions.

Nesson, E. (2017). The impact of tobacco control policies on adolescent smoking: comparing self-reports and biomarkers. American Journal of Health Economics, 3(4):507-527.

Newey, W. K. (1990). Efficient instrumental variables estimation of nonlinear models. Econometrica: Journal of the Econometric Society, pages 809-837. 
Nguimkeu, P., Denteh, A., and Tchernis, R. (2019). On the estimation of treatment effects with endogenous misreporting. Journal of econometrics, 208(2):487-506.

Rees, D. I. and Sabia, J. J. (2010). Body weight and smoking initiation: Evidence from add health. Journal of Health Economics, 29(5):774-777. 
Table 1: Estimates from Previous Literature where BMI is Dependent Variable

\begin{tabular}{lccccl}
\hline Study & Indep. Var. & Data & Method & Estimate & Interpretation \\
\hline Smoking Increases BMI & & & & & \\
\hline Gruber and Frakes (2006) & Smoking Status & BRFSS 1984-2002 & 2SLS & 5.705 & Effect of smoking using cigarette taxes as an instrument \\
Courtemanche (2009) & Cigarette Prices & BRFSS 1984-2005 & OLS & -0.234 & $\begin{array}{l}\text { Effect of a } \$ 1 \text { increase in real price of cigarettes } \\
\text { Effect of a } \$ 1 \text { increase in real cigarette taxes }\end{array}$ \\
Courtemanche (2009) & Cigarette Taxes & NLSY 1979 & OLS & -0.343 & \\
\hline Smoking Decreases BMI & & & & & \\
\hline Chou et al. (2004) & Cigarette Prices & BRFSS 1984-2002 & OLS & 0.486 & Effect of a \$1 increase in real price of cigarettes \\
Baum (2009) & Cigarette Taxes & NLSY 1979 & OLS & 0.328 & Effect of a \$1 increase in real cigarette taxes \\
Baum (2009) & Cigarette Prices & NLSY 1979 & OLS & 0.162 & Effect of a \$1 increase in real price of cigarettes \\
Fang et al. (2009) & Smoking Status & China Health and & 2SLS & -0.124 & Effect of a one-cigarette increase in smoking (instruments: \\
& & Nutrition Survey 2006 & & & community smoking rate, cigarette prices) \\
Liu et al. (2010) & Smoking Status & BRFSS 1998-2006 & 2SLS & -2.054 & Effect of workplace smoking bans \\
Courtemanche et al. (2018) & Smoking Status & Lung Health Study & RCT/2SLS & -2.202 & Effect of smoking cessation treatment
\end{tabular}


Table 2: Summary Statistics

\begin{tabular}{lcccccc}
\hline & \multicolumn{2}{c}{ Non-Smoker } & \multicolumn{2}{c}{ Smoker } & \multicolumn{2}{c}{ Full Sample } \\
& Mean & SD & Mean & SD & Mean & SD \\
\hline BMI & 27.77 & 5.47 & 27.18 & 5.41 & 27.65 & 5.46 \\
Current Cigarette Smoker & - & - & - & - & 0.21 & 0.41 \\
Cigarette Tax (2017 \$) & 2.25 & 1.06 & 2.10 & 1.03 & 2.22 & 1.06 \\
Male & 0.43 & 0.49 & 0.46 & 0.50 & 0.43 & 0.50 \\
Black & 0.08 & 0.28 & 0.09 & 0.29 & 0.08 & 0.28 \\
White & 0.78 & 0.42 & 0.77 & 0.42 & 0.78 & 0.42 \\
Hispanic & 0.08 & 0.27 & 0.06 & 0.24 & 0.07 & 0.26 \\
Married & 0.63 & 0.48 & 0.43 & 0.49 & 0.59 & 0.49 \\
Divorced & 0.13 & 0.34 & 0.23 & 0.42 & 0.15 & 0.36 \\
Widowed & 0.03 & 0.17 & 0.05 & 0.21 & 0.03 & 0.18 \\
Grade 9-11 & 0.03 & 0.18 & 0.10 & 0.31 & 0.05 & 0.22 \\
High School & 0.24 & 0.43 & 0.38 & 0.49 & 0.27 & 0.44 \\
Technical Degree & 0.27 & 0.45 & 0.31 & 0.46 & 0.28 & 0.45 \\
College Graduate & 0.44 & 0.50 & 0.18 & 0.38 & 0.38 & 0.49 \\
Disposition Rate & 0.93 & 0.26 & 0.92 & 0.27 & 0.93 & 0.26 \\
Income (2017 \$) & 69,497 & 38,164 & 48,445 & 35,449 & 65,088 & 38,575 \\
State Unemployment Rate & 5.96 & 2.09 & 5.97 & 2.04 & 5.96 & 2.08 \\
\hline Observations & $2,843,312$ & & 753,331 & & $3,596,643$ & \\
\hline
\end{tabular}


Table 3: Variation in Nominal Cigarette Taxes (2002-2017)

\begin{tabular}{|c|c|c|c|}
\hline State & Tax in January $2002(\$)$ & Tax in Dec 2017 (\$) & No. of increases \\
\hline Alabama & 0.165 & 0.675 & 2 \\
\hline Alaska & 1 & 2 & 3 \\
\hline Arizona & 0.60 & 2 & 2 \\
\hline Arkansas & 0.34 & 1.15 & 2 \\
\hline California & 0.87 & 2.87 & 1 \\
\hline Colorado & 0.20 & 0.84 & 1 \\
\hline Connecticut & 0.50 & 4.35 & 8 \\
\hline Delaware & 0.24 & 2.10 & 4 \\
\hline District of Columbia & 0.65 & 2.50 & 2 \\
\hline Florida & 0.339 & 1.339 & 1 \\
\hline Georgia & 0.12 & 0.37 & 1 \\
\hline Hawaii & 1 & 3.2 & 9 \\
\hline Idaho & 0.28 & 0.57 & 1 \\
\hline Illinois & 0.58 & 1.98 & 2 \\
\hline Indiana & 0.155 & 0.995 & 2 \\
\hline Iowa & 0.36 & 1.36 & 1 \\
\hline Kansas & 0.24 & 1.29 & 3 \\
\hline Kentucky & 0.03 & 0.60 & 3 \\
\hline Louisiana & 0.24 & 1.08 & 3 \\
\hline Maine & 1 & 2 & 1 \\
\hline Maryland & 0.66 & 2 & 2 \\
\hline Massachusetts & 0.76 & 3.51 & 3 \\
\hline Michigan & 0.75 & 2 & 2 \\
\hline Minnesota & 0.48 & 3.04 & 5 \\
\hline Mississippi & 0.18 & 0.68 & 1 \\
\hline Missouri & 0.17 & 0.17 & 0 \\
\hline Montana & 0.18 & 1.70 & 2 \\
\hline Nebraska & 0.34 & 0.64 & 1 \\
\hline Nevada & 0.35 & 1.80 & 2 \\
\hline New Hampshire & 0.52 & 1.78 & 5 \\
\hline New Jersey & 0.80 & 2.70 & 5 \\
\hline New Mexico & 0.21 & 1.66 & 2 \\
\hline New York & 1.11 & 4.35 & 3 \\
\hline North Carolina & 0.05 & 0.45 & 3 \\
\hline North Dakota & 0.44 & 0.44 & 0 \\
\hline Ohio & 0.24 & 1.60 & 3 \\
\hline Oklahama & 0.23 & 1.03 & 1 \\
\hline Oregon & 0.68 & 1.32 & 4 \\
\hline Pennsylvania & 0.31 & 2.60 & 4 \\
\hline Rhode Island & 1 & 4.25 & 7 \\
\hline South Carolina & 0.07 & 0.57 & 1 \\
\hline South Dakota & 0.33 & 1.53 & 2 \\
\hline Tennessee & 0.13 & 0.62 & 2 \\
\hline Texas & 0.41 & 1.41 & 1 \\
\hline Utah & 0.515 & 1.70 & 2 \\
\hline Vermont & 0.44 & 3.08 & 7 \\
\hline Virginia & 0.025 & 0.30 & 2 \\
\hline Washington & 1.425 & 3.025 & 3 \\
\hline West Virginia & 0.17 & 1.20 & 2 \\
\hline Wisconsin & 0.77 & 2.52 & 2 \\
\hline Wyoming & 0.12 & 0.60 & 1 \\
\hline
\end{tabular}


Table 4: Effect of Smoking on BMI

\begin{tabular}{|c|c|c|c|}
\hline & (1) & $(2)$ & (3) \\
\hline \multicolumn{4}{|c|}{ First Stage: Regress Smoking Status on Cigarette Taxes } \\
\hline 2SLS & $\begin{array}{c}-0.005^{* * *} \\
(0.002) \\
{[9.18]}\end{array}$ & $\begin{array}{c}-0.015^{* * *} \\
(0.003) \\
{[20.77]}\end{array}$ & $\begin{array}{c}-0.006^{* * *} \\
(0.001) \\
{[16.38]}\end{array}$ \\
\hline 2-Step & $\begin{array}{c}-0.005^{* * *} \\
(0.002) \\
{[128.16]}\end{array}$ & $\begin{array}{c}-0.018^{* * *} \\
(0.000) \\
{[66.90]}\end{array}$ & $\begin{array}{c}-0.008^{* *} \\
(0.000) \\
{[36.95]}\end{array}$ \\
\hline NFI \& CF & $\begin{array}{c}-0.006^{* * *} \\
(0.002) \\
{[6.74]}\end{array}$ & $\begin{array}{c}-0.016^{* * *} \\
(0.004) \\
{[20.48]}\end{array}$ & $\begin{array}{c}-0.006^{* * *} \\
(0.002) \\
{[11.38]}\end{array}$ \\
\hline \multicolumn{4}{|c|}{ Linear Reduced Form: Regress BMI on Cigarette Taxes } \\
\hline Cigarette Taxes & $\begin{array}{l}-0.019 \\
(0.050)\end{array}$ & $\begin{array}{c}0.012 \\
(0.048)\end{array}$ & $\begin{array}{l}-0.025 \\
(0.042)\end{array}$ \\
\hline \multicolumn{4}{|c|}{ Second Stage: Regress BMI on Predicted Smoking Status } \\
\hline OLS & $\begin{array}{c}-0.404^{* * *} \\
(0.085)\end{array}$ & $\begin{array}{c}-0.707^{* * *} \\
(0.089)\end{array}$ & $\begin{array}{c}-0.707^{* * *} \\
(0.080)\end{array}$ \\
\hline 2SLS & $\begin{array}{c}3.489 \\
(8.260)\end{array}$ & $\begin{array}{c}-0.792 \\
(3.081)\end{array}$ & $\begin{array}{c}4.200 \\
(6.302)\end{array}$ \\
\hline 2-Step & $\begin{array}{c}-0.678 \\
(1.484)\end{array}$ & $\begin{array}{l}-0.495 \\
(0.937)\end{array}$ & $\begin{array}{c}-1.059^{* *} \\
(0.499)\end{array}$ \\
\hline NFI & $\begin{array}{c}-20.890 \\
(16.168)\end{array}$ & $\begin{array}{c}-4.526^{* * *} \\
(1.248)\end{array}$ & $\begin{array}{c}-6.210^{* * *} \\
(0.631)\end{array}$ \\
\hline $\mathrm{CF}$ & $\begin{array}{r}-11.270 \\
(8.615)\end{array}$ & $\begin{array}{c}-5.482^{* * *} \\
(1.510)\end{array}$ & $\begin{array}{c}-7.366^{* * *} \\
(0.760)\end{array}$ \\
\hline Observations & $3,596,643$ & $3,596,643$ & $3,596,643$ \\
\hline State FE & $\checkmark$ & & $\checkmark$ \\
\hline Quarter-Year FE & $\checkmark$ & & $\checkmark$ \\
\hline All covariates & & $\checkmark$ & $\checkmark$ \\
\hline
\end{tabular}

Standard errors are presented in parentheses and are robust to clustering at the state-level. F / Chi-Square statistics are presented in brackets. Data are from the BRFSS 2002-2017. We weight observations by BRFSS-provided survey weights. Estimators include ordinary least squares (OLS), instrumental variables (2SLS), Newey correction to the forbidden regression (NFI), the control function approach (CF), and 2-step to correct for misreporting (2S). For comparison purposes, the first stage estimates for NFI and CF that we present are obtained by calculating the marginal effects. The first stage estimates for $2 \mathrm{~S}$ that we present are obtained by regressing predicted true smoking status on cigarette taxes and controls via OLS. Note: the coefficient on the disposition variable in the first stage of the 2-step estimator is -0.021 (s.e. is 0.010). * $\mathrm{p}<0.10, * * \mathrm{p}<0.05, * * * \mathrm{p}<0.01$. 
Table 5: Effect of Smoking on BMI, Using Both Taxes and Disposition as Instruments

\begin{tabular}{|c|c|c|c|c|c|c|}
\hline \multirow[b]{2}{*}{ VARIABLES } & \multicolumn{3}{|c|}{ Linear Approach } & \multicolumn{3}{|c|}{ Nonlinear Approaches } \\
\hline & $\begin{array}{c}\text { First Stage } \\
\text { Smoking Status }\end{array}$ & $\begin{array}{c}\text { Reduced Form } \\
\text { BMI }\end{array}$ & $\begin{array}{l}2 \mathrm{SLS} \\
\mathrm{BMI}\end{array}$ & $\begin{array}{c}\text { First Stage } \\
\text { Smoking Status }\end{array}$ & $\begin{array}{l}\text { NFI } \\
\text { BMI }\end{array}$ & $\begin{array}{c}\mathrm{CF} \\
\mathrm{BMI}\end{array}$ \\
\hline Cigarette Taxes & $\begin{array}{c}-0.006 * * * \\
(0.001)\end{array}$ & $\begin{array}{l}-0.026 \\
(0.042)\end{array}$ & & $\begin{array}{c}-0.006 * * * \\
(0.002)\end{array}$ & & \\
\hline Disposition & $\begin{array}{c}-0.007 * * \\
(0.003)\end{array}$ & $\begin{array}{c}0.389 * * * \\
(0.024)\end{array}$ & & $\begin{array}{c}-0.007 * * \\
(0.003)\end{array}$ & & \\
\hline Smoker & & & $\begin{array}{c}-20.131 * * \\
(9.643)\end{array}$ & & $\begin{array}{c}-6.481 * * * \\
(0.655)\end{array}$ & $\begin{array}{c}-7.694 * * * \\
(0.790)\end{array}$ \\
\hline Observations & $3,596,643$ & $3,596,643$ & $3,596,643$ & $3,596,643$ & $3,596,643$ & $3,596,643$ \\
\hline
\end{tabular}

Standard errors are presented in parentheses and are robust to clustering at the state-level. Data are from the BRFSS 2002-2017. We weight observations by BRFSS-provided survey weights. Estimators include instrumental variables (2SLS), Newey correction to the forbidden regression (NFI), and the control function approach (CF). All specifications include the full set of covariates and fixed effects. For comparison purposes, the first stage estimates for NFI and CF that we present are obtained by calculating the marginal effects. ${ }^{*} \mathrm{p}<0.10, * * \mathrm{p}<0.05, * * * \mathrm{p}<0.01$. 
Table 6: Effect of Smoking on BMI by Age

\begin{tabular}{lccccc}
\hline \multicolumn{7}{c}{ OLS } & 2SLS & 2-Step & NFI & CF \\
\hline Panel A: Age 18-40 & \multicolumn{7}{c}{ First Stage (DV = Smoking Status, Mean 0.224) } \\
\hline \multirow{3}{*}{ Cigarette Taxes } & - & $-0.006^{* * *}$ & $-0.008^{* * *}$ & $-0.006^{* *}$ & $-0.006^{* *}$ \\
& - & $(0.002)$ & $(0.000)$ & $(0.003)$ & $(0.003)$ \\
& - & {$[8.62]$} & {$[75.27]$} & {$[5.17]$} & {$[5.17]$} \\
\hline \multirow{5}{*}{ Second Stage (DV = BMI, Mean 26.7) } \\
\cline { 2 - 6 } & $-0.195^{* *}$ & 4.039 & $-4.217^{* * *}$ & $-2.575^{* * *}$ & $-3.276^{* * *}$ \\
Observations & $1,218,758$ & $1,218,758$ & $1,218,758$ & $1,218,758$ & $1,218,758$ \\
\hline
\end{tabular}

Panel B: Age 41-65

\begin{tabular}{lccccc}
\hline & \multicolumn{5}{c}{ First Stage (DV = Smoking Status, Mean 0.205) } \\
\cline { 2 - 6 } Cigarette Taxes & - & $-0.006^{* * *}$ & $-0.011^{* * *}$ & $-0.006^{* * *}$ & $-0.006^{* * *}$ \\
& - & $(0.001)$ & $(0.000)$ & $(0.001)$ & $(0.001)$ \\
& - & {$[23.46]$} & {$[31.19]$} & {$[21.99]$} & {$[21.99]$} \\
\hline \multirow{5}{*}{ Second Stage (DV = BMI, Mean 28.1) } \\
\cline { 2 - 6 } Smoking Status & $-1.422^{* * *}$ & 4.112 & -0.784 & $-6.058^{* * *}$ & $-7.184^{* * *}$ \\
& $(0.079)$ & $(4.690)$ & $(0.791)$ & $(0.485)$ & $(0.595)$ \\
Observations & $2,377,885$ & $2,377,885$ & $2,377,885$ & $2,377,885$ & $2,377,885$ \\
\hline
\end{tabular}

All specifications include covariates, year-quarter fixed effects, and state fixed effects. Standard errors are presented in parentheses and are robust to clustering at the state-level. F / Chi-Square statistics are presented in brackets. Data are from the BRFSS 2002-2017. We weight observations by BRFSS-provided survey weights. Estimators include ordinary least squares (OLS), instrumental variables (2SLS), Newey correction to the forbidden regression (NFI), the control function approach (CF), and 2-step to correct for misreporting (2S). For comparison purposes, the first stage estimates for NFI and CF that we present are obtained by calculating the marginal effects. The first stage estimates for $2 \mathrm{~S}$ that we present are obtained by regressing predicted true smoking status on cigarette taxes and controls via OLS. $* \mathrm{p}<0.10$, ** $\mathrm{p}<0.05$, *** $\mathrm{p}<0.01$. 
Table 7: Effect of Smoking on BMI by Gender

\begin{tabular}{|c|c|c|c|c|c|}
\hline & OLS & 2SLS & 2-Step & NFI & $\mathrm{CF}$ \\
\hline \multicolumn{6}{|l|}{ Panel A: Male } \\
\hline \multirow{4}{*}{ Cigarette Taxes } & \multicolumn{5}{|c|}{ First Stage $(\mathrm{DV}=$ Smoking Status, Mean 0.233) } \\
\hline & - & $-0.005^{* * *}$ & $-0.006^{* * *}$ & $-0.005^{* * *}$ & $-0.005^{* * *}$ \\
\hline & - & $(0.002)$ & $(0.000)$ & $(0.002)$ & $(0.002)$ \\
\hline & - & [7.57] & [76.07] & {$[6.77]$} & {$[6.77]$} \\
\hline \multirow[b]{2}{*}{ Smoking Status } & \multicolumn{5}{|c|}{ Second Stage (DV = BMI, Mean 27.8) } \\
\hline & $\begin{array}{c}-0.778^{* * *} \\
(0.091)\end{array}$ & $\begin{array}{c}3.871 \\
(5.632)\end{array}$ & $\begin{array}{c}-6.893^{* * *} \\
(0.499)\end{array}$ & $\begin{array}{c}-4.514^{* * *} \\
(0.532)\end{array}$ & $\begin{array}{c}-4.844^{* * *} \\
(0.579)\end{array}$ \\
\hline Observations & $1,564,310$ & $1,564,310$ & $1,564,310$ & $1,564,310$ & $1,564,310$ \\
\hline \multicolumn{6}{|l|}{ Panel B: Female } \\
\hline \multirow{4}{*}{ Cigarette Taxes } & \multicolumn{5}{|c|}{ First Stage (DV = Smoking Status, Mean 0.194) } \\
\hline & - & $-0.007^{* * *}$ & $-0.012^{* * *}$ & $-0.007^{* * *}$ & $-0.007^{* * *}$ \\
\hline & - & $(0.001)$ & $(0.000)$ & $(0.002)$ & $(0.002)$ \\
\hline & - & {$[24.56]$} & {$[25.25]$} & {$[14.58]$} & {$[14.58]$} \\
\hline & \multicolumn{5}{|c|}{ Second Stage (DV = BMI, Mean 27.0) } \\
\hline Smoking Status & $\begin{array}{c}-0.521^{* * *} \\
(0.078)\end{array}$ & $\begin{array}{c}3.214 \\
(6.941)\end{array}$ & $\begin{array}{c}1.296 \\
(0.976)\end{array}$ & $\begin{array}{c}-0.876^{* *} \\
(0.392)\end{array}$ & $\begin{array}{c}-1.002^{*} \\
(0.509)\end{array}$ \\
\hline Observations & $2,032,333$ & $2,032,333$ & $2,032,333$ & $2,032,333$ & $2,032,333$ \\
\hline
\end{tabular}

All specifications include covariates, year-quarter fixed effects, and state fixed effects. Standard errors are presented in parentheses and are robust to clustering at the state-level. F / Chi-Square statistics are presented in brackets. Data are from the BRFSS 2002-2017. We weight observations by BRFSS-provided survey weights. Estimators include ordinary least squares (OLS), instrumental variables (2SLS), Newey correction to the forbidden regression (NFI), the control function approach (CF), and 2-step to correct for misreporting (2S). For comparison purposes, the first stage estimates for NFI and CF that we present are obtained by calculating the marginal effects. The first stage estimates for $2 \mathrm{~S}$ that we present are obtained by regressing predicted true smoking status on cigarette taxes and controls via OLS. $* \mathrm{p}<0.10$, ** $\mathrm{p}<0.05$, *** $\mathrm{p}<0.01$. 
Table 8: Effect of Smoking on BMI: By Census Region

\begin{tabular}{|c|c|c|c|c|}
\hline & $\mathrm{NE}$ & MW & $\mathrm{SO}$ & WE \\
\hline $\begin{array}{l}\text { First Stage: Regress Smoking Status on Cigarette Taxes } \\
\text { Mean of DV }\end{array}$ & 0.208 & 0.239 & 0.231 & 0.171 \\
\hline 2SLS & $\begin{array}{c}-0.006^{* * *} \\
(0.002) \\
{[13.31]}\end{array}$ & $\begin{array}{c}-0.009^{* *} \\
(0.003) \\
{[7.85]}\end{array}$ & $\begin{array}{c}-0.009 \\
(0.006) \\
{[2.77]}\end{array}$ & $\begin{array}{c}-0.000 \\
(0.002) \\
{[0.00]}\end{array}$ \\
\hline 2-Step & $\begin{array}{c}-0.007^{* * *} \\
(0.000) \\
{[10.15]}\end{array}$ & $\begin{array}{c}-0.008^{* * *} \\
(0.000) \\
{[24.43]}\end{array}$ & $\begin{array}{c}-0.013^{*} \\
(0.000) \\
{[4.99]}\end{array}$ & $\begin{array}{c}0.002^{* * *} \\
(0.000) \\
{[10.92]}\end{array}$ \\
\hline NFI \& CF & $\begin{array}{c}-0.007^{* * *} \\
(0.002) \\
{[10.63]}\end{array}$ & $\begin{array}{c}-0.010^{* * *} \\
(0.003) \\
{[9.17]}\end{array}$ & $\begin{array}{c}-0.011^{*} \\
(0.006) \\
{[3.50]}\end{array}$ & $\begin{array}{c}0.001 \\
(0.002) \\
{[0.39]}\end{array}$ \\
\hline $\begin{array}{l}\text { Second Stage: Regress BMI on Predicted Smoking Status } \\
\text { Mean of DV }\end{array}$ & 27.1 & 27.6 & 27.7 & 27.0 \\
\hline OLS & $\begin{array}{c}-0.507^{* * *} \\
(0.092)\end{array}$ & $\begin{array}{c}-0.799^{* * *} \\
(0.064)\end{array}$ & $\begin{array}{c}-0.932^{* * *} \\
(0.086)\end{array}$ & $\begin{array}{l}-0.340^{*} \\
(0.160)\end{array}$ \\
\hline $2 \mathrm{SLS}$ & $\begin{array}{l}15.345^{* * *} \\
(1.914)\end{array}$ & $\begin{array}{c}1.233 \\
(5.931)\end{array}$ & $\begin{array}{c}3.901 \\
(4.456)\end{array}$ & $\begin{array}{c}-3,394 \\
(344,919)\end{array}$ \\
\hline 2-Step & $\begin{array}{c}-3.198^{* * *} \\
(0.654)\end{array}$ & $\begin{array}{c}-4.492^{* * *} \\
(0.389)\end{array}$ & $\begin{array}{c}0.673 \\
(0.577)\end{array}$ & $\begin{array}{l}-0.900 \\
(0.742)\end{array}$ \\
\hline NFI & $\begin{array}{c}-5.741^{* * *} \\
(0.830)\end{array}$ & $\begin{array}{c}-6.904^{* * *} \\
(0.804)\end{array}$ & $\begin{array}{l}-5.825^{* * *} \\
(0.406)\end{array}$ & $\begin{array}{c}-6.330^{* * *} \\
(0.800)\end{array}$ \\
\hline $\mathrm{CF}$ & $\begin{array}{c}-6.521^{* * *} \\
(0.969)\end{array}$ & $\begin{array}{c}-7.680^{* * *} \\
(0.926)\end{array}$ & $\begin{array}{c}-7.111^{* * *} \\
(0.544)\end{array}$ & $\begin{array}{c}-7.180^{* * *} \\
(0.892)\end{array}$ \\
\hline Observations & 696,936 & 879,807 & $1,122,084$ & 897,816 \\
\hline
\end{tabular}

All specifications include covariates, year-quarter fixed effects, and state fixed effects. Standard errors are presented in parentheses and are robust to clustering at the state-level. F / Chi-Square statistics are presented in brackets. Data are from the BRFSS 2002-2017. We weight observations by BRFSS-provided survey weights. Estimators include ordinary least squares (OLS), instrumental variables (2SLS), Newey correction to the forbidden regression (NFI), the control function approach (CF), and 2-step to correct for misreporting (2S). For comparison purposes, the first stage estimates for NFI and CF that we present are obtained by calculating the marginal effects. The first stage estimates for $2 \mathrm{~S}$ that we present are obtained by regressing predicted true smoking status on cigarette taxes and controls via OLS. $* \mathrm{p}<0.10, * * \mathrm{p}<0.05$, $* * * \mathrm{p}<0.01$. 